\title{
The 100 top-cited studies on postoperative hyperalgesia in the last 30 years: a bibliometric analysis
}

\author{
Tianyao Zhang ${ }^{1,2 \#}$, Xiaochu Wu ${ }^{1 \#}$, Yu Ye ${ }^{1,2}$, Jun $\mathrm{Ma}^{1,2}$, Cheng Zhou ${ }^{1,2}$, Peng Liang ${ }^{3}$, Bin Liu ${ }^{1,2}$ \\ ${ }^{1}$ Department of Anesthesiology and National Clinical Research Center for Geriatrics, West China Hospital of Sichuan University, Chengdu, China; \\ ${ }^{2}$ Laboratory of Anesthesia and Critical Care Medicine, Translational Neuroscience Center, West China Hospital of Sichuan University, Chengdu, \\ China; ${ }^{3}$ Day Surgery Center, Department of Anesthesiology, West China Hospital, Sichuan University and The Research Units of West China \\ (2018RU012), Chinese Academy of Medical Sciences, Chengdu, China \\ Contributions: (I) Conception and design: T Zhang, X Wu; (II) Administrative support: B Liu, P Liang; (III) Provision of study materials or patients: \\ C Zhou; (IV) Collection and assembly of data: T Zhang, X Wu; (V) Data analysis and interpretation: T Zhang, X Wu, Y Ye, J Ma; (VI) Manuscript \\ writing: All authors; (VII) Final approval of manuscript: All authors. \\ "These authors contributed equally to this work. \\ Correspondence to: Peng Liang, MD. Day Surgery Center, Department of Anesthesiology, West China Hospital, Sichuan University and The Research \\ Units of West China (2018RU012), Chinese Academy of Medical Sciences, Chengdu, China. Email: liangpengwch@scu.edu.cn; Bin Liu, MD. \\ Department of Anesthesiology, West China Hospital of Sichuan University, Chengdu, China. Email: linbinhxyy@163.com.
}

Background In recent years, the issue of postoperative pain has raised wide concern in the medical community. Postoperative hyperalgesia $(\mathrm{POH})$, as the primary etiology of pain, has been extensively studied and numerous articles have been published on this topic; however, no comprehensive bibliometric review of $\mathrm{POH}$ publications has been conducted. Thus, we aimed to examine the 100 top-cited reports on $\mathrm{POH}$ and summarize their key characteristics.

Methods: Published studies on POH were retrieved from the Web of Science Core Collection (WoSCC) using the search terms "postoperative hyperalgesia". All papers published since 1980 were searched. The search results were sorted by the frequency of the total citations, and 2 reviewers independently skimmed the abstracts and full texts to identify the 100 top-cited reports. After the 100 top-cited papers were identified, the following data were extracted by the two reviewers: the title, surname(s) of the author(s), name of the first author, publication year, country of origin, article type, institutional affiliations, keywords, source journal, and impact factor (IF) of the journal.

Results: The initial search returned 1,747 papers, published in 466 journals that originated from 1,679 institutions in 48 countries. The 100 top-cited reports received 21,454 citations. The USA was the most cited and most productive country, contributing nearly half of the 100 top-cited papers. The numbers of studies on $\mathrm{POH}$ have trended upward and continue to increase each year.

Conclusions: An analysis of the 100 top-cited studies on $\mathrm{POH}$ provided a better guidance for ongoing researches. The prominent keywords "opioid-induced hyperalgesia", especially "remifentanil”, is still on top of $\mathrm{POH}$ research area. Nevertheless, the mechanism of $\mathrm{POH}$ is intricate and unclear, which is crucial to conduct further studies and find some new interventions.

Keywords: Postoperative hyperalgesia (POH); pain; bibliometric analysis; citations

Submitted Oct 21, 2021. Accepted for publication Nov 25, 2021.

doi: 10.21037/apm-21-3240

View this article at: https://dx.doi.org/10.21037/apm-21-3240 


\section{Introduction}

Postoperative hyperalgesia $(\mathrm{POH})$ is a common clinical condition characterized by pain hypersensitivity, a decreased threshold for pain, and allodynia. The two main types of $\mathrm{POH}$ are primary hyperalgesia and secondary hyperalgesia. Primary hyperalgesia is caused by an original incision and disappears as the wound heals. Secondary hyperalgesia, also known as central hyperalgesia, involves functional changes in synaptic plasticity that are induced by noxious stimuli. Opioid-induced hyperalgesia, the most common type of hyperalgesia, is one of typical secondary hyperalgesia, which is related to increasing doses of opioid drugs.

$\mathrm{POH}$ is an important branch of perioperative pain. Opioids can cause $\mathrm{POH}$; however, these drugs are also the primary therapy for perioperative pain management. Remifentanil, for example, is considered a key opioid drug in the development of $\mathrm{POH}(1,2)$. Consequently, the prophylaxis and prevention of $\mathrm{POH}$ has been the subject of increasing attention in recent years. For example, a systematic review of the Cochrane library demonstrated that perioperative intravenous ketamine reduces postoperative opioid consumption and pain intensity, and does not result in adverse events (3). Preemptive analgesia (4,5) and opioidfree anesthesia $(6,7)$ have also gradually been developed. In addition, several studies on the mechanisms of $\mathrm{POH}$ have been conducted $(8,9)$.

Given the current state of the POH literature, we sought to examine the status of the research in this area, and identify popular areas and the frontiers of $\mathrm{POH}$ research. To date, although there were some reviews about $\mathrm{POH}$, a bibliometric analysis of the $\mathrm{POH}$ literature has not been conducted. A bibliometric analysis is a novel analysis framework for giving influential research evidence. Hence, it is eager to summarize $\mathrm{POH}$ in this new way. VOSviewer is a Java-based computer program used to visualize patterns and trends in scientific literature by co-occurrence and cluster analyses $(10,11)$. In this paper, we used VOSviewer and bibliometric.com to perform a bibliometric review of the 100 top-cited reports on POH from the Web of Science Core Collection (WoSCC), and conducted an analysis of the current achievements and the development directions in this field.

\section{Methods}

The WoSCC was searched using the search terms "postoperative hyperalgesia" on April 5, 2021, and studies published on $\mathrm{POH}$ were retrieved. All papers published since 1980 were searched. The obtained search results were sorted by the frequency of the total citations.

Two reviewers independently skimmed the abstracts and full texts to identify the 100 top-cited reports. To be included in the analysis, the study had to focus on $\mathrm{POH}$. Irrelevant studies were discarded. After the 100 top-cited papers were selected, the following data were extracted by the two reviewers from the papers: the title, surname(s) of the author(s), name of the first author, publication year, institutional affiliations, country of origin, article type, keywords, source journal, and impact factor (IF) of the journal.

\section{Statistical analysis}

All data were collected and analyzed in Microsoft EXCEL (2016) software.

\section{Results}

In total, 1,747 reports were retrieved from the WoSCC database using the terms "postoperative hyperalgesia" (see Figure S1). With the exception of 1 paper published in 1982, studies in this area first began to be published in 1991 , and there has been a gradual increase in the number of publications per year since then. Over the last 5 years, a peak in publications has occurred, indicating that $\mathrm{POH}$ is a popular topic and will likely continue to be so in the near future. The retrieved papers were published in 466 journals, and originated from 1,679 institutions in 48 different countries.

\section{The citation characteristics of the 100 top-cited studies on $\mathrm{POH}$}

The 100 top-cited studies are listed in Table S1 in descending order of the number of total citations. The studies were published between 1991 and 2016. The number of citations per paper ranged from 107 to 1,909 , and the total citation number for the studies was 21,454 . The most-cited report titled, "Central sensitization: implications for the diagnosis and treatment of pain", was a review of the mechanisms involved in pain with a focus on central sensitization. This study was published in the journal Pain, and emphasized the effects of activity-dependent synaptic plasticity in the spinal cord on central sensitization, and outlined the genetic and environmental contributors to 
Table 1 Journals that published the 100 top-cited POH studies.

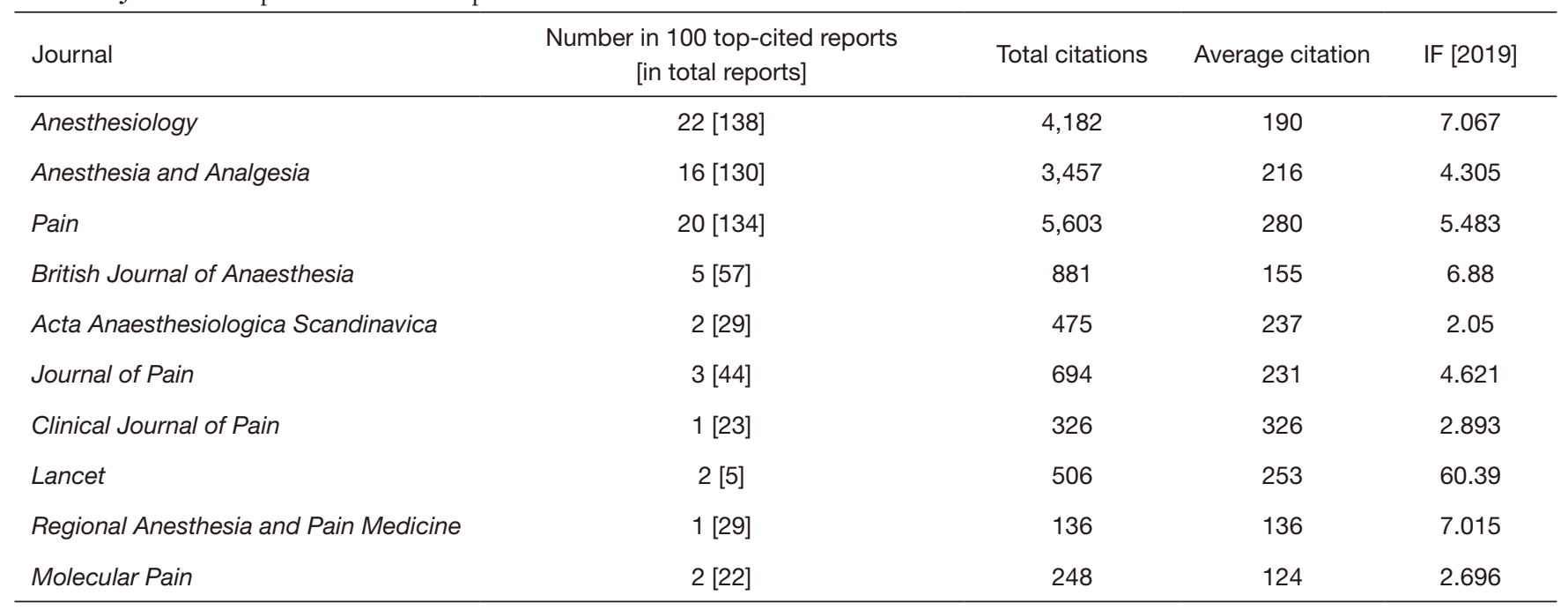

$\mathrm{POH}$, postoperative hyperalgesia; IF, impact factor.

this phenomenon. The second most frequently cited paper titled, "Preemptive analgesia treating postoperative pain by preventing the establishment of central sensitization", was a review of postoperative pain and central sensitization that examined treatment by preemptive analgesia. This review was cited by other studies 1,059 times. Interestingly, the top 1 and 2 most-cited papers shared the same first author (i.e., Woolf CJ). The third most-cited POH study, titled "Characterization of a rat model of incisional pain", was also published in Pain and had been cited 747 times. The authors of this study established a rat model of postoperative incisional pain, which was a necessary first step for many subsequent studies on $\mathrm{POH}$.

\section{Fournals that have published POH studies}

The top 10 journals that published the greatest number of POH studies are listed in Table 1 in descending order based on the number of total citations. The top 3 journals publishing POH studies were Anesthesiology ( $\mathrm{n}=138)$, Anesthesia and Analgesia $(\mathrm{n}=130)$, and Pain $(\mathrm{n}=134)$. Among these top 10 journals, the contributions to the 100 top-cited studies were as follows: 22 were published in Anesthesiology, 16 were published Anesthesia and Analgesia, 20 were published in Pain, 5 were published in the British Fournal of Anaesthesia, and 3 were published in the Fournal of Pain. Two studies were published in each of the following journals: Acta Anaesthesiologica Scandinavica, Molecular Pain, and the
Lancet. The other 2 journals, Regional Anesthesia and Pain Medicine and the Clinical Fournal of Pain, published 1 study each among the 100 top-cited reports. The total number of citations for publications appearing in each journal ranged from 136 to 5,603. The articles published in Pain received the most citations. $\mathrm{POH}$ articles published in the Clinical Fournal of Pain had the highest average citation rate per paper at 326 citations. The IFs of these 10 journals in 2019 ranged from 2.05 to 60.39 . The highest IF journal was the Lancet, which published 5 studies of the 1,747 reports, and 2 of the 100 top-cited studies.

\section{Publication years for the 100 top-cited $\mathrm{POH}$ studies}

The 100 top-cited studies were published between 1992 and 2016 (see Table 2). The greatest number of studies was published in 2003 ( $\mathrm{n}=10)$, followed by 2004 and 2005 $(\mathrm{n}=9), 1997(\mathrm{n}=8)$, and 2001, 2002, and $2011(\mathrm{n}=6)$. Studies published in 2011 had the highest number of total citations $(\mathrm{n}=2,733)$, and the highest average number of citations per paper $(n=462)$.

\section{Type of studies among the 100 top-cited POH studies}

Of the 100 top-cited publications, 78 were primary research articles, 21 were reviews, and 1 was an editorial. The number of studies (78 vs. 21), total citations $(19,087 \mathrm{vs}$. $2,248)$, and average citations per paper (245 vs. 107) were 
Table 2 Publication years for the 100 top-cited POH studies

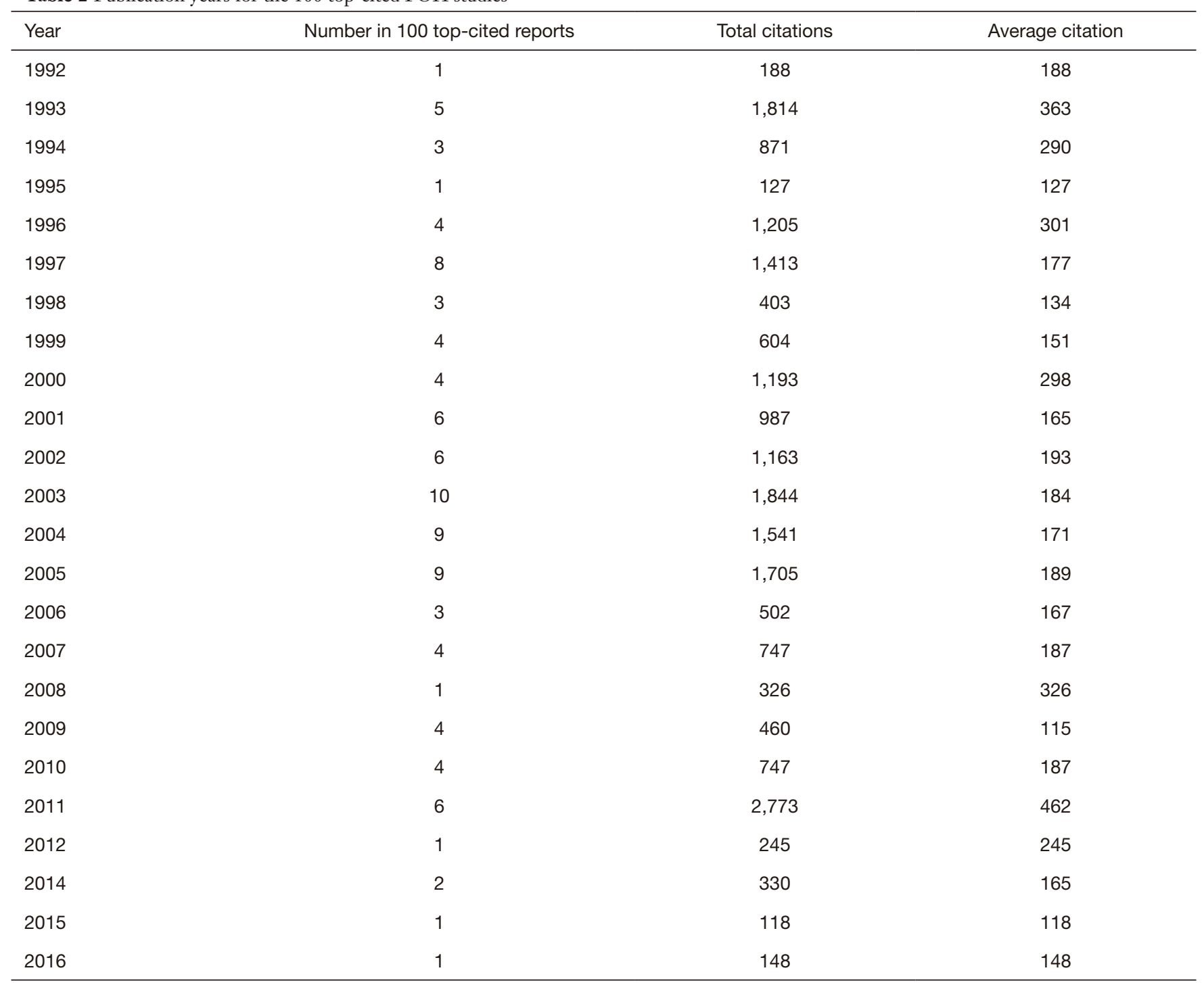

$\mathrm{POH}$, postoperative hyperalgesia.

higher for original research articles than reviews. The 100 top-cited studies were divided into 12 categories by the Web of Science, with the top 3 being anesthesiology $(\mathrm{n}=68)$, neurosciences $(\mathrm{n}=6)$, and clinical neurology $(\mathrm{n}=5$; see Table 3).

\section{Countries of origin for the 100 top-cited $\mathrm{POH}$ studies}

Among the 100 top-cited studies, 48 were from the USA. Approximately a quarter of the studies originating in the USA were co-authored by researchers in other countries, such as Germany, Canada, Japan, or China, followed by
Denmark and France $(\mathrm{n}=10)$, and Germany and the UK $(\mathrm{n}=8)$. Canada, Israel, and the Netherlands contributed 2 studies each, while China and Austria contributed 3 studies each (see Table 4).

\section{Institutions associated with at least five of the 100 top-cited POH studies}

A total of 8 institutions from 6 countries contributed 5 or more publications each to the 100 top-cited $\mathrm{POH}$ studies (see Table 5). The institutions associated with the most $\mathrm{POH}$ publications were located in the USA, and included the 
Table 3 Types of studies among the 100 top-cited POH studies

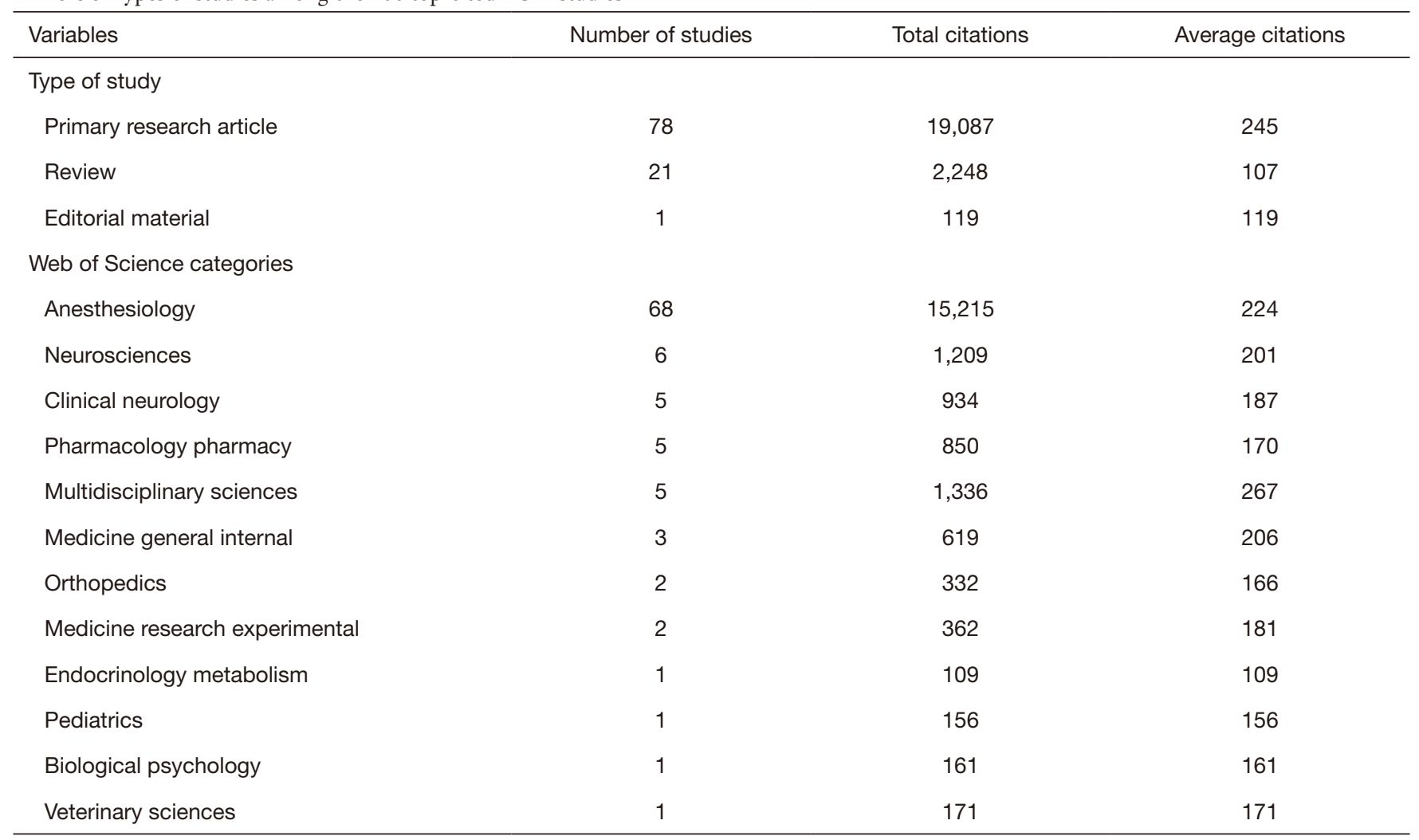

$\mathrm{POH}$, postoperative hyperalgesia.

Table 4 Countries of origin for the 100 top-cited POH studies

\begin{tabular}{lcc}
\hline Country & $\begin{array}{c}\text { Number in } 100 \text { top-cited } \\
\text { reports }\end{array}$ & Total citations \\
\hline USA & 48 & 11,966 \\
Denmark & 10 & 1,451 \\
France & 10 & 2,355 \\
Germany & 8 & 1,431 \\
UK & 8 & 2,185 \\
Canada & 5 & 738 \\
Israel & 5 & 902 \\
Netherlands & 5 & 667 \\
Austria & 3 & 807 \\
China & 3 & 397 \\
\hline
\end{tabular}

$\mathrm{POH}$, postoperative hyperalgesia.

University of Iowa ( $\mathrm{n}=11$ ), the University of Louisville, and Harvard University ( $\mathrm{n}=7$ each) The Ambroise Pare Hospital in France, Tel Aviv University in Israel, and the University
Table 5 Institutions associated with at least 5 of the 100 top-cited $\mathrm{POH}$ studies

\begin{tabular}{lc}
\hline Name of institutions & Number in 100 cited reports \\
\hline The University of lowa & 11 \\
The University of Louisville & 7 \\
Harvard University & 7 \\
Ambroise Pare Hospital & 6 \\
Tel Aviv University & 6 \\
The University of Toronto & 6 \\
University of Erlangen-Nuremberg & 5 \\
Nihon University & 5 \\
\hline POH, postoperative hyperalgesia. &
\end{tabular}

of Toronto in Canada were associated with 6 publications each. Two institutions (i.e., the University of ErlangenNuremberg and Nihon University) were associated with 5 publications each. Of the 8 institutions, 7 were universities, and 3 were located in the USA. 
Table 6 The top 10 high-frequency keywords in the 100 top-cited POH studies and all POH studies retrieved

\begin{tabular}{|c|c|c|c|c|}
\hline No. & \multicolumn{2}{|c|}{100 top-cited studies } & \multicolumn{2}{|c|}{ All studies } \\
\hline 1 & Hyperalgesia & 47 & Hyperalgesia & 816 \\
\hline 2 & Postoperative pain & 38 & Postoperative pain & 765 \\
\hline 3 & Analgesia & 21 & Analgesia & 324 \\
\hline 5 & Pain & 16 & Pain & 312 \\
\hline 6 & Neuropathic pain & 13 & Morphine & 276 \\
\hline 7 & Allodynia & 13 & Surgery & 227 \\
\hline 8 & Rat & 11 & Ketamine & 216 \\
\hline
\end{tabular}

$\mathrm{POH}$, postoperative hyperalgesia. No., number.

\section{Co-occurring keywords}

The analysis of high-frequency keywords in publications can help to identify popular topics in a research field. As Table 6 shows, the most frequent keywords among both the 100 top-cited $\mathrm{POH}$ studies and all the retrieved $\mathrm{POH}$ studies were hyperalgesia (frequency in top 100: 47, overall frequency: 816), postoperative pain (frequency in top 100: 38, overall frequency: 765), and analgesia (frequency in top 100: 21, overall frequency: 324). Other top keywords included morphine (frequency in top 100: 20, overall frequency: 276), pain (frequency in top 100: 16, overall frequency: 312 ), neuropathic pain (frequency in top 100: 13, overall frequency: 322), and surgery (frequency in top 100: 10, overall frequency: 227). Other top keywords in the 100 top-cited studies included rat (frequency: 11), allodynia (frequency: 13), and spinal cord (frequency: 9), while the other top keywords in the total number of reports retrieved included ketamine (frequency: 216), opioidinduced hyperalgesia (frequency: 210), and remifentanil (frequency: 180).

\section{Discussion}

Postoperative pain is a key medical issue that has received increasing attention from surgeons and anesthesiologists in recent years. Several perioperative pain management methods have been developed to aid in the prophylaxis and prevention of this condition. $\mathrm{POH}$ is one of the main pathogenic mechanisms involved in postoperative pain, and has also been the subject of increased research attention. Despite the increasing number of reports published on this topic, a bibliometric analysis of publications in this field had yet to be conducted. A bibliometric review of postoperative pain after non-surgical root canal therapy (12) had been published; however, it only included 424 papers. This analysis alone is not enough to develop a deep understanding of the $\mathrm{POH}$ research field. Thus, we carried out a detailed bibliometric analysis to provide a comprehensive view of the $\mathrm{POH}$ field, and help researchers gain a better understanding of the literature.

One thousand seven hundred and forty-seven POHrelated papers, published in the last 30 years, were retrieved from the WoSCC database. Except for 1 paper published in 1982, the others were published after 1991, and the number of publications per year showed a continuous upward trend. In relation to the 100 top-cited POH reports, the publication timeline ran from 1991 to 2016, and the number of papers per year approximated a normal distribution. Studies published from 2003 to 2005 comprised nearly $30 \%$ of the top 100 most-cited papers. These characteristics indicate that $\mathrm{POH}$, as a term, has gradually come into usage since the 1990s. In the past 5 years, the highest number of $\mathrm{POH}$-related reports have been published, totaling more than 100 per year. These findings show that $\mathrm{POH}$ has gained continued attention in the past 20 years. Thus, $\mathrm{POH}$ is a popular topic of research in the field of perioperative pain, and will likely continue to be so in the coming years.

Most of the 100 top-cited $\mathrm{POH}$ papers originated in 
the USA. Indeed, approximately half of the studies were conducted in the USA (48 of 100). In addition, the top 3 institutions associated with the most highly cited $\mathrm{POH}$ articles were located in USA. Thus, the USA was the most productive country in this field. Among the countries from which the 100 top-cited $\mathrm{POH}$ reports originated, most were developed countries, except for Israel. Developed countries probably contributed the majority of the 100 top-cited studies, as they have better research funding and infrastructure. High-quality studies require the constant accumulation of data, which in turn requires a large number of preliminary experiments and significant investment.

The 100 top-cited $\mathrm{POH}$ studies were cited from 107 to 1,909 times and published in 30 journals between 1992 and 2016. The number of total citations has increased with time. Among the 100 top-cited studies, only 11 were published in the last 10 years. The relatively low number of citations for studies published in the past 10 years should not be taken as an indicator of significance, as citations require time to accumulate. Twenty-two of the 100 topcited studies were published in the Anesthesiology journal. These 22 published papers had the highest total number of citations (4,182 times). Of the top 5 journals with the most highly cited $\mathrm{POH}$ articles, 4 were centered on the field of anesthesiology. Thus, $\mathrm{POH}$ has gained increasing attention from anesthesiologists and related professionals, and professional journals may be more likely to publish POH-related research. Notably, the Lancet published 5 articles related to $\mathrm{POH}$, and 2 of the studies published by this journal were among the 100 top-cited reports, receiving 506 citations. Thus, POH may be considered a popular research topic, as studies in this area have been published in a prestigious journal with a high IF.

Among the 100 top-cited studies, 78\% were primary research articles that were cited 19,087 times and, according to the Web of Science categorization, $68 \%$ were within the field of anesthesiology. This latter finding suggests that anesthesiology-related professionals paid a great deal of attention to $\mathrm{POH}$ research. The analysis of co-occurring keywords showed that there were some similarities and differences between the 100 top-cited studies, and all the retrieved studies related to $\mathrm{POH}$. Among the top 10 high-frequency keywords, 7 keywords (i.e., hyperalgesia, postoperative pain, analgesia, morphine, pain, neuropathic pain, and surgery) were shared across all papers. All the studies frequently used the keywords ketamine, morphineinduced hyperalgesia, and remifentanil, while the 100 top- cited reports were tendency to use the terms allodynia, rat, and spinal cord. Based on these differences, we concluded that $\mathrm{POH}$ studies primarily focused on opioid-induced hyperalgesia, especially in relation to remifentanil, while the top-cited papers were more likely to be primary research articles focused on animal research. Opioid, widely used in the analgesia administration, is related to acute tolerance and hyperalgesia, in which both of them could lead to adverse outcomes. In recent studies, multiple-model analgesia has been come up with to prevent $\mathrm{POH}$, and some new therapeutic methods have appeared, such as $35 \%$ $\mathrm{N}_{2} \mathrm{O}$ (13) and magnesium sulfate (14). The mechanism of $\mathrm{POH}$ was still unclear and complex, further studies could focus on its pathogenetic mechanism, from which the direction of new drug research and invention will be sought out.

There are still some limitations in this bibliometric analysis. First, only WoSCC database was searched for paper collection, we could miss some related $\mathrm{POH}$ papers published in the other databases. Further studies will include Medline, the Cochrane library and Google Scholar and so on. Secondary, citations did not totally represent the quality of publications. However, we believe that this metric plays a valid role on behalf of influence within this research field around the world. To date, just a small quantity of bibliometric reviews focusing on "postoperative pain". Ali Nosrat paid more attention to pain after root canal treatment, while Qi Li kept an eye on publication trends and hot spots in chronic postsurgical pain (CPSP). In this review, we take more care about $\mathrm{POH}$, which differs from CPSP. This is the first bibliometric analysis in the terms of $\mathrm{POH}$.

In conclusion, our study provides a comprehensive list of the true landmark publications on $\mathrm{POH}$, and recognizes the contributions made by important authors, institutions, and scientific journals. This bibliometric analysis described the overall structure of scientific research for this field and provided collective information to assist other researchers. Given the rising number of surgeries, $\mathrm{POH}$ is likely to remain a crucial research area in the future.

\section{Acknowledgments}

Funding: This study was supported by the Science and Technology Project of the Health Planning Committee of Sichuan (18PJ175) and the Project of the Max Cynader Academy of Brain Workstation, WCHSCU (HXYS 19005). 


\section{Footnote}

Conflicts of Interest: All authors have completed the ICMJE uniform disclosure form (available at https://dx.doi. org/10.21037/apm-21-3240). The authors have no conflicts of interest to declare.

Ethical Statement: The authors are accountable for all aspects of the work in ensuring that questions related to the accuracy or integrity of any part of the work are appropriately investigated and resolved.

Open Access Statement: This is an Open Access article distributed in accordance with the Creative Commons Attribution-NonCommercial-NoDerivs 4.0 International License (CC BY-NC-ND 4.0), which permits the noncommercial replication and distribution of the article with the strict proviso that no changes or edits are made and the original work is properly cited (including links to both the formal publication through the relevant DOI and the license). See: https://creativecommons.org/licenses/by-nc-nd/4.0/.

\section{References}

1. Santonocito C, Noto A, Crimi C, et al. Remifentanilinduced postoperative hyperalgesia: current perspectives on mechanisms and therapeutic strategies. Local Reg Anesth 2018;11:15-23.

2. Koo CH, Yoon S, Kim BR, et al. Intraoperative naloxone reduces remifentanil-induced postoperative hyperalgesia but not pain: a randomized controlled trial. Br J Anaesth 2017;119:1161-8.

3. Brinck EC, Tiippana E, Heesen M, et al. Perioperative intravenous ketamine for acute postoperative pain in adults. Cochrane Database Syst Rev 2018;12:CD012033.

4. Katz J, Cohen L, Schmid R, et al. Postoperative morphine use and hyperalgesia are reduced by preoperative but not intraoperative epidural analgesia: implications for preemptive analgesia and the prevention of central sensitization. Anesthesiology 2003;98:1449-60.

Cite this article as: Zhang $\mathrm{T}, \mathrm{Wu} \mathrm{X}, \mathrm{Ye} \mathrm{Y}, \mathrm{Ma} \mathrm{J}$, Zhou C, Liang P, Liu B. The 100 top-cited studies on postoperative hyperalgesia in the last 30 years: a bibliometric analysis. Ann Palliat Med 2021;10(12):12538-12545. doi: 10.21037/apm-21-3240
5. Simonnet G. Preemptive antihyperalgesia to improve preemptive analgesia. Anesthesiology 2008;108:352-4.

6. Bello M, Oger S, Bedon-Carte S, et al. Effect of opioidfree anaesthesia on postoperative epidural ropivacaine requirement after thoracic surgery: a retrospective unmatched case-control study. Anaesth Crit Care Pain Med 2019;38:499-505.

7. Soffin EM, Wetmore DS, Beckman JD, et al. Opioidfree anesthesia within an enhanced recovery after surgery pathway for minimally invasive lumbar spine surgery: a retrospective matched cohort study. Neurosurg Focus 2019;46:E8.

8. Shi C, Liu Y, Zhang W, et al. Intraoperative electroacupuncture relieves remifentanil-induced postoperative hyperalgesia via inhibiting spinal glial activation in rats. Mol Pain 2017;13:1744806917725636.

9. Song C, Liu P, Zhao Q, et al. TRPV1 channel contributes to remifentanil-induced postoperative hyperalgesia via regulation of NMDA receptor trafficking in dorsal root ganglion. J Pain Res 2019;12:667-77.

10. van Eck NJ, Waltman L. Citation-based clustering of publications using CitNetExplorer and VOSviewer. Scientometrics 2017;111:1053-70.

11. van Eck NJ, Waltman L. Software survey: VOSviewer, a computer program for bibliometric mapping. Scientometrics 2010;84:523-38.

12. Nosrat A, Dianat O, Verma P, et al. Postoperative pain: an analysis on evolution of research in half-century. J Endod 2021;47:358-65.

13. Wehrfritz A, Bauer M, Noel N, et al. Evaluation of antihyperalgesic and analgesic effects of $35 \%$ nitrous oxide when combined with remifentanil: A randomised phase 1 trial in volunteers. Eur J Anaesthesiol 2021;38:1230-41.

14. Silva Filho SE, Sandes CS, Vieira JE, et al. Analgesic effect of magnesium sulfate during total intravenous anesthesia: randomized clinical study. Braz J Anesthesiol 2021;71:550-7.

(English Language Editor: L. Huleatt) 
Supplementary

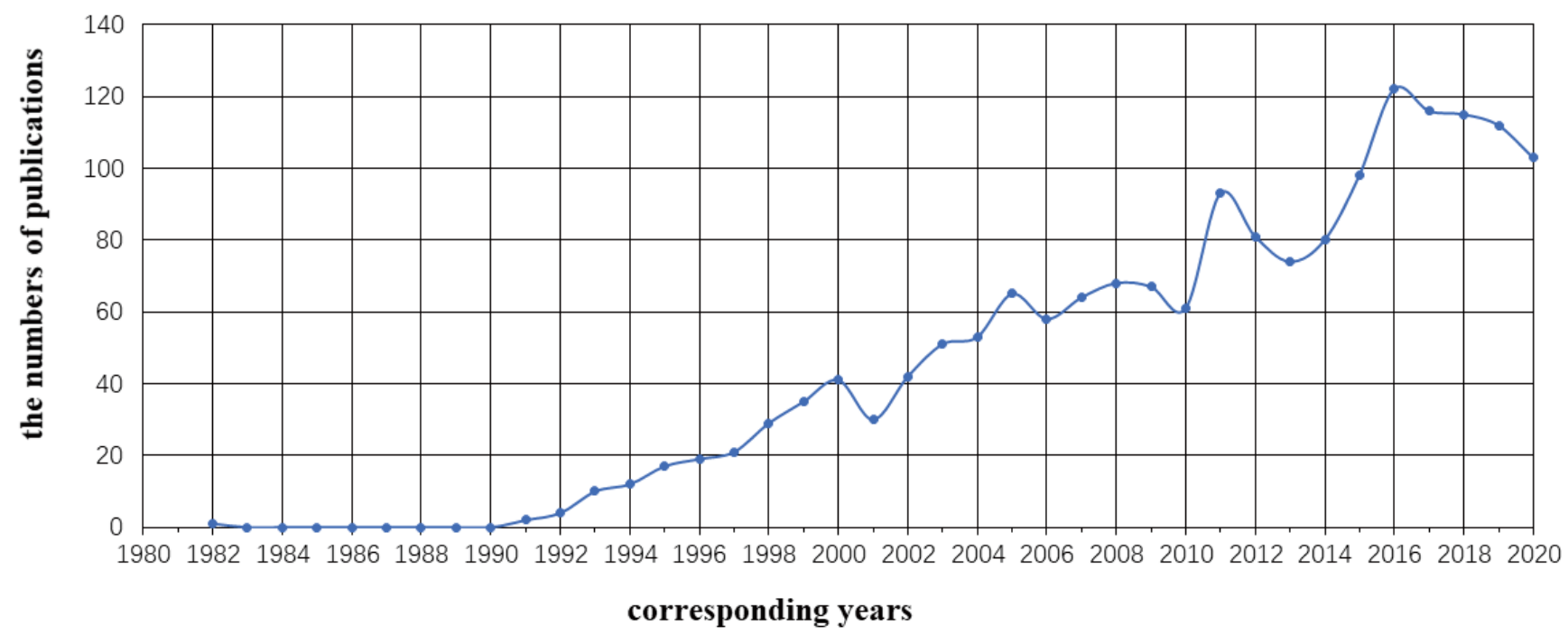

Figure S1 Distributions of all retrieved papers related "postoperative hyperalgesia" according to years. 


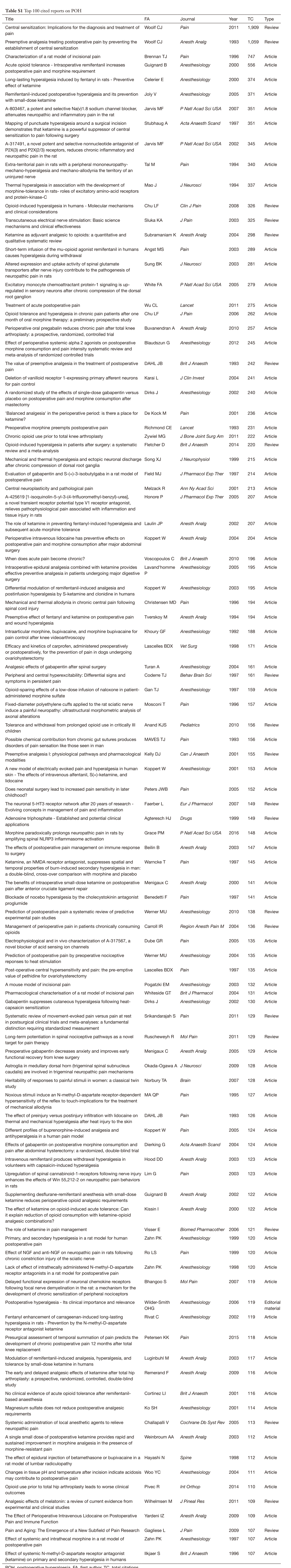

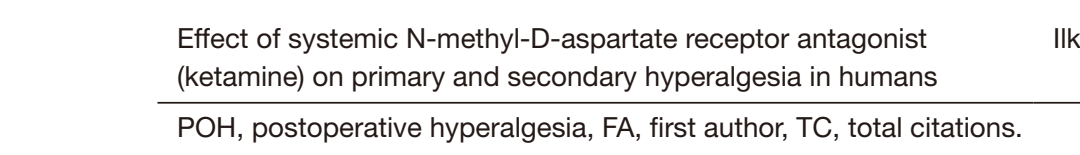

